\title{
Gear Tooth Health State Monitoring Based on Morphological Filtering and Wavelet Transition
}

\author{
http://dx.doi.org/10.3991/ijoe.v9iS2.2563 \\ H.Z. Feng, W. Liang, L.B. Zhang, J.W. Shi \\ China University of Petroleum-Beijing, Beijing, China
}

\begin{abstract}
Gear box is one of the most important transmission components in mechanical systems. Fault diagnosis and state monitoring techniques for gear box have been studied for years. But in practical, gear box usually works under varying work conditions which has not been considered in most studies. In this paper, a novel state monitoring method is proposed for monitor gear box work with varying conditions. The vibration signal is de-nosied by morphological filtering. Then gear-mesh frequency band is extracted by wavelet transform. Dimensionless time indexes are used as state monitoring features. A regularization method is proposed to calculate gear tooth health index. Simulate and experiment signal are presented to illustrate the effectiveness of the method. The result indicates that, morphological filtering is an efficient method to de-nosie the vibration signal; wavelet transform can extract the gearmesh frequency band; gear tooth health index can monitor gear tooth state based on vibration signal.
\end{abstract}

Index Terms-gear tooth, health index, varying work conditions, morphological filtering, wavelet transition.

\section{INTRODUCTION}

Gear transmission is widely used in rotating machines for its compacter structure and higher transition efficiency compared to other transmission types. Generally, gear transmission often used in different critical conditions. Once it fails, failure often causes linkage failures and will bring system failures which will cause huge finance loss or even personal injury. The important structure and economic status of gear transmission makes it necessary to study its diagnosis and monitoring technologies

The vibration signal based method is the most widely used diagnosis and monitoring technology. Because the signal collected usually contains a lot of noises from varying vibration sources, the de-noise technologies has been discussed and studied widely and profundity. Conventional siganal de-noise filters can not increase the resolution ratio and signal noise ratio simultaneously. EMD (Empirical Mode Decomposition) denoise method [1] has difficult to determine the physical significance of IMF (Intrinsic Mode Function) which restricted its use in application. Wavelet thresholding denoise method [2] and its derivative methods have good application effect. But it is difficult to determine the suitable threshold which highly relies on experience. SVD (singular value decomposition) denoise method has a shortage of no confirm method in determing the embedding dimensions. Morphological filtering is a non-linear filter method based on mathematical morphology. It decomposes the signal into different physical meaning parts by mathematical morphology change. Then extract useful signals from background signals while maintain the main signal morphological characteristics. The method has been widely used in image processing [3], power quality [4] and signal processing [5]. In this paper, a novel multiscale and multielement morphological filtering method is proposed to effectively filtering multi types of nosies and well reserve the details of signal characteristics.

There has been a lot of research achievements focused in the diagnosis of fixed work condition gear transmission which is not adapted well in practical because most of the gear boxes work under varying conditions. Viliam Makis [6] and his colleagues discussed condition based maintenace (CBM) policies of gear box under different loads. But his work mainly emphasis the policy optimazation and whole life cycle maintenance management.

In this study, for gear work in vary conditions, we propose a gear tooth failure diagnosis technology and gear state monitoring method.

\section{MORPHOLOGICAL FILTERING}

Morphological filtering method is initially proposed by Maragos in 1980s [7]. Different from other time or frequency domain method, It uses assemble to describe the target signal. Its basic idea is to design a filtering window to match the signal without consider any frequency domain elements.

Morphologic translation contains 4 basic compute modes: erosion, dilation, open and close operation. Considering the vibration signal is one-dimensional signal, gray value morphologic translation with discrete onedimension situation is discussed.

Define original signal $f(n)$ as discrete function of $F=(0,1, \Lambda, N-1)$. Define structural elements $g(m)$ as discrete function of $G=(0,1, \Lambda, M-1) . N>>M$. Then define the erosion, dilation operation as equation (1) and (2).

$$
\begin{aligned}
& (f \Theta g)(n)=\min (f(n+m)-g(m)) \\
& (f \oplus g)(n)=\max (f(n-m)+g(m))
\end{aligned}
$$

Where $n \in F, m \in G$. (4).

Define the open and close operation as equation (3) and

$$
\begin{aligned}
& (f \circ g)(n)=(f \Theta g \oplus g)(n) \\
& (f \bullet g)(n)=(f \oplus g \Theta g)(n)
\end{aligned}
$$

Symbols $\mathrm{o}$ and $\bullet$ indicate the the open and close operation respectively. Open operation can eliminate the isolated points and make the signal smooth. Close 
operation can fill the gaps and filtering the negative pulse noise. It can be concluded that morphologic translation only contains Boolean, addition and subtraction operations instead of multiply or divide operations which means it is simple and efficient.

To eliminate the positive and negative noise at the same time, Maragos [7] defined morphologic open-closing and close-opening filter as equation (5) and (6).

$$
\begin{aligned}
& \operatorname{FOC}(f(n))=(f \circ g \bullet g)(n) \\
& \operatorname{FCO}(f(n))=(f \bullet g \circ g)(n)
\end{aligned}
$$

Because of the statistical deviation phenomenon, morphologic open-closing and close-opening filter is normally used as cascade form.

The key element of morphologic filter is the size and shape of the structural elements. Different structual elements can eliminate specific noise type. To solve the element optimazation problem, a new multiscale and multielement morphological filtering method is proposed.

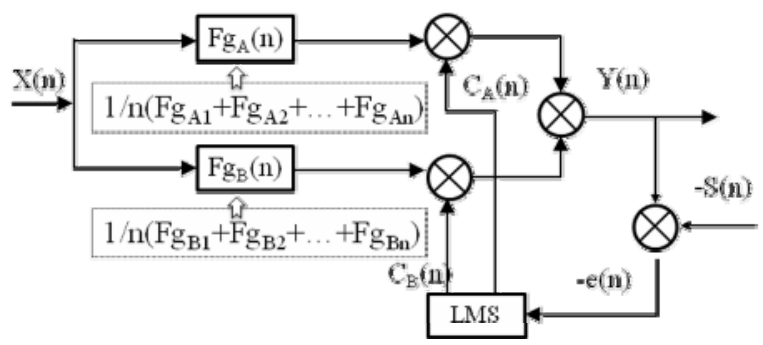

Figure 1. Mechanism map of adaptive generalized morphological filtering

As shown in Fig.1, define input signal is $\mathrm{X}(\mathrm{n}), \mathrm{n}=1,2, \Lambda, \mathrm{N}$. Define $\mathrm{S}(\mathrm{n})$ as ideal signal. Define $Y(n)$ as output signal after filtering. Define $e(n)$ as the error signal between ideal signal and output signal. Define $\mathrm{Fg}_{\mathrm{Ai}}$ as the signal been filtered by multi A type structural elements $g_{\mathrm{Ai}}$. Define $\mathrm{Fg}_{\mathrm{Bi}}$ as the signal been filtered by multi B type structural elements $g_{\mathrm{Bi}} \cdot \mathrm{C}_{\mathrm{A}}(n)$ and $\mathrm{C}_{\mathrm{B}}(n)$ is the weight coefficients of different structural elements.

In this study, parabola and triangle structure elements are chosen considering the specialty of gear signal.

\section{A. Morphology Filtering based on LMS Self-adaption algorithm}

A novel self-adaptive filtering method is proposed in this section. After chosen different structure elements, an update cascade morphological filter is constructed based on self-adaptive weight distribution

$$
Y(n)=C_{A}(\mathrm{n}) * \mathrm{Fg}_{\mathrm{A}}(n)+C_{B}(\mathrm{n}) * \mathrm{Fg}_{\mathrm{B}}(n)
$$

Where $\mathrm{C}_{\mathrm{A}}(n)+\mathrm{C}_{\mathrm{B}}(n)=1$. The mean square error of output signal is shown in equation (8).

$$
\begin{aligned}
& \mathrm{E}\left[\mathrm{e}^{2}(\mathrm{n})\right]=E\left[(Y(n)-S(n))^{2}\right]= \\
& E\left[\left(S(n)=\sum_{x=A, B} C_{x}(n) F g_{A}(n)\right)^{2}\right]
\end{aligned}
$$

Then LMS algorithm is adopted to amend $\mathrm{C}_{\mathrm{A}}(n)$ and $\mathrm{C}_{\mathrm{B}}(n)$ in order to make output signal $\mathrm{Y}(\mathrm{n})$ approach the ideal signal $\mathrm{S}(\mathrm{n})$ based on minimum variance principle. Use single sample's mean square error $\mathrm{e}^{2}(\mathrm{n})$ as estimation value of mean square error $E\left[\mathrm{e}^{2}(n)\right]$. Then calculate the partial derivative to $\mathrm{C}_{\mathrm{i}}(n)$ as equation (9).

$$
\frac{\partial\left[\mathrm{e}^{2}(\mathrm{n})\right]}{\partial \mathrm{a}_{\mathrm{x}}(n)}=-2 F g_{x}(n) e(n), x=A, B
$$

Then, equation (10) is established by steepest descent method.

$$
\mathrm{C}_{\mathrm{x}}(n+1)=C_{x}(n)-\mu \frac{\partial\left[\mathrm{e}^{2}(\mathrm{n})\right]}{\partial \mathrm{a}_{\mathrm{x}}(n)}, x=A, B
$$

Substitute equation (8) into equation (10).

$$
\begin{aligned}
& \mathrm{C}_{\mathrm{x}}(n+1)= \\
& C_{x}(n)+2 \mu \mathrm{Fg}_{x}(n) e(n), x=A, B
\end{aligned}
$$

In equation (11), $\mu$ is the convergence rate control parameter.

\section{B. Simulate Signal Analysis}

As shown in Fig.2, the simulate signal is a Doppler signal with gaussian noise.
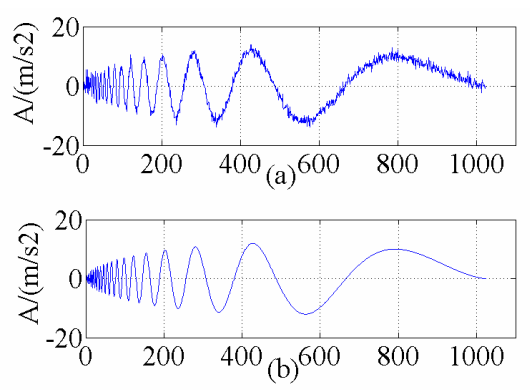

Figure 2. (a)Simulated signal with noise (b)Simulated signal

The simulate signal is denoised by soft threshold wavelet method, SVD filter method and adaptive generalized morphological filtering method respectively. The result is shown in Fig.3.
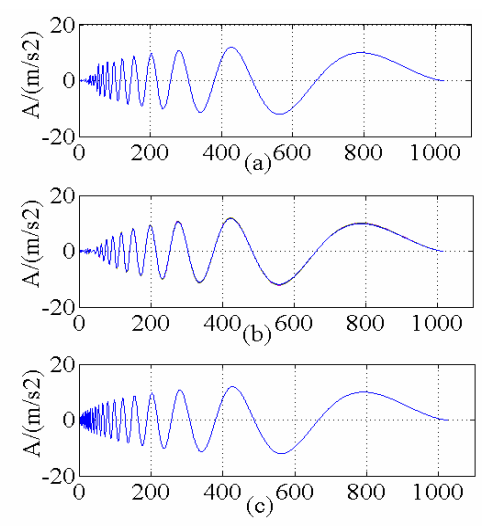

Figure 3. (a) Soft-threshold wavelet filtering (b) SVD filtering (c) Adaptive generalized morphological filtering 
Fig.3 indicates that the signal processed by softthreshold wavelet filtering and SVD filtering has serious distortion in high frequency band. Adaptive generalized morphological filtering method can de-noise the signal efficiently while keep the useful information.

The evaluation parameters of different methods are summed in table 1 . It can be concluded that the signal denoised by adaptive-generalized morphological-filtering has the highest accurate rate and lowest mean square errors.

TABLE I.

EVALUATION PARAMETERS OF DIFFERENT METHODS

\begin{tabular}{|c|c|c|c|}
\hline & Coefficient & SNR & $\begin{array}{c}\text { mean } \\
\text { square } \\
\text { error }\end{array}$ \\
\hline $\begin{array}{c}\text { Soft-threshold wavelet- } \\
\text { filtering }\end{array}$ & $99.78 \%$ & 54.41 & 14.94 \\
\hline SVD-filtering & $98.63 \%$ & 31.27 & 17.57 \\
\hline $\begin{array}{c}\text { Adaptive-generalized } \\
\text { morphological-filtering }\end{array}$ & $100.00 \%$ & 125.17 & 0.43 \\
\hline
\end{tabular}

\section{WAVELET TRANSITION AND SPECIFIC FREQUENCY} BAND CHOSE

Wavelet transition can decomposite signals into different frequency bands. When gear running in healthy state, the vibration signal will include mesh frequency and side frequencies. When tooth failure occurs, failure features would appear around the mesh frequencies. There are many wavelet basis disigned for different signals. Daubechies40 wavelet basis is adopted in this study as its excellent performances in former studies [8].

Fig.4 indicates the method of extract gear mesh frequency by wavelet transition. Firstly, apply wavelet decomposition to the signal and makes gear mesh frequency in the middle of decomposite frequency band cDn. Secondely, reconstruct the signal while setting other frequency band to 0 .

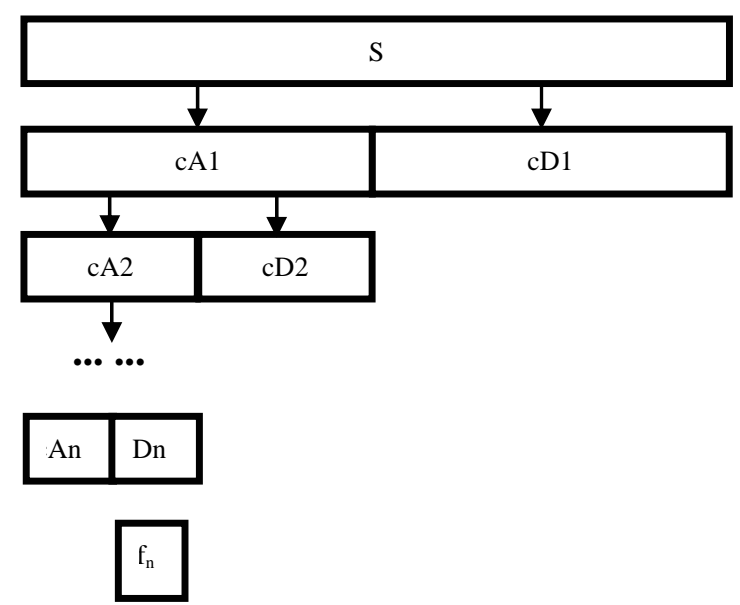

Figure 4. Wavelet transform to extract gear meshing frequency (fn)

The rotation frequency is defined as $f_{c}$, the gear tooth number is $\mathrm{N}$, thus the gear mesh frequency $\mathrm{f}_{\mathrm{n}}=\mathrm{N} \bullet \mathrm{f}_{\mathrm{c}}$. Define the analysis frequency as $F_{s}$, thus the frequency band of $n$ level wavelet decomposition is $\mathrm{D}=\mathrm{F}_{\mathrm{s}} / 2 \mathrm{n}$. $\mathrm{n}=\log _{2}\left(\mathrm{~F}_{\mathrm{s}} / \mathrm{D}\right)$. Then, when $\left\{(\mathrm{i}+0.3) \mathrm{D} \leqq \mathrm{f}_{\mathrm{n}} \leqq(\mathrm{i}+0.6) \mathrm{D}\right.$, $\mathrm{i}=0,1,2 \cdots\}$, the wavelet transition will makes $\mathrm{f}_{\mathrm{n}}$ in the middle of cDn frequency band.

\section{GEAR TOOTH HEALTH INDEX CALCULATION}

Considering vary loads condition, nondimensional parameters pulse index and margin index which can characterize the amount of impact energy is chosed as characteristic values.

Pulse index and margin index are calculated by equation (12) and (13) respectively.

$$
\begin{gathered}
I=\frac{\mathrm{x}_{\mathrm{p}}}{\mathrm{X}^{\prime}}=\frac{\text { peak value }}{\text { average value }} \\
L=\frac{\mathrm{X}_{\mathrm{p}}}{\mathrm{x}_{\mathrm{r}}}=\frac{\text { peak value }}{\text { mean square amplitude }}
\end{gathered}
$$

The gear tooth failure has a degradation process. It will gradually deteriorate from brand new state to tooth brake failure. As shown in equation (14), a new concept of health index is proposed to describe the health state of gear tooth.

$$
H=1-\frac{\left(I_{n}-I_{\min }\right) /\left(I_{\max }-I_{\min }\right)+\left(L_{n}-L_{\min }\right) /\left(L_{\max }-L_{\min }\right)}{2}
$$

Where $\mathrm{H}$ indicates the health index, $\mathrm{I}_{\mathrm{n}}$ and $\mathrm{L}_{\mathrm{n}}$ are pulse index and margin index of the monitoring gear. $\mathrm{I}_{\min }$ and $\mathrm{L}_{\min }$ are pulse index and margin index of health gear. $\mathrm{I}_{\max }$ and $\mathrm{L}_{\max }$ are pulse index and margin index of tooth failure gear. Thus after collect the indexes of health and failure gears, the monitoring gear tooth health index $\mathrm{H}$ between $0 \sim 1$ can be easily calculated by the normalization calculate as equation (14). When $\mathrm{H}$ is close to 1 , the gear state get close to brand new; When $\mathrm{H}$ is close to 0 , the gear state get close to tooth failure.

\section{EXPERIMENT}

The gear box vibration data is collected from the selfdesigned gear box test bed. As shown in Fig. 5 A, the test bed is a two stage reduction gear tansmission system. The 1 st stage gear ratio is $34 / 92$. And the 2 nd stage gear ratio is $46 / 81$.

The gear box vibration signal is collected by a multichannel fault diagnostic instrument. The sample fruquency is $12800 \mathrm{~Hz}$.

As shown in Fig.5 B, the gear tooth failure is realized by cut $1 / 3$ of the bigger middle shaft gear. The failure gear has been run under the same working conditions as healthy gear. The vary work conditions include: 300rpm, 600rpm and with/without load (100N.m).

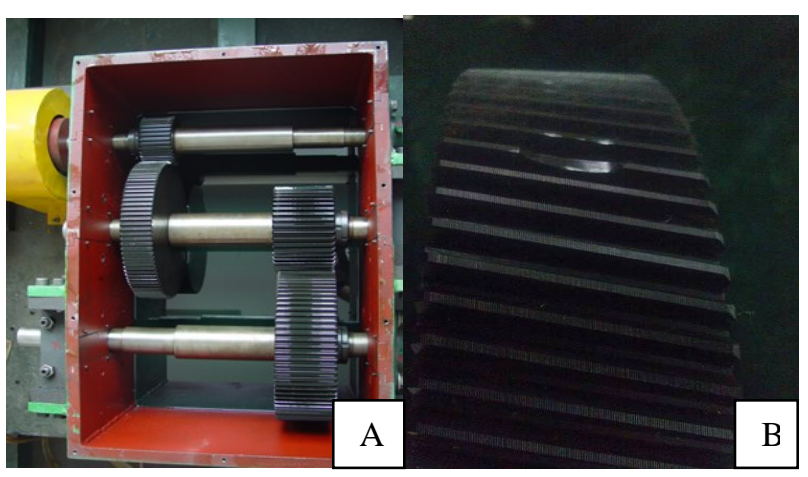

Figure 5. A.Gear box test bed; B.Gear tooth failure 


\section{RESULTS AND DISCUSSION}

For rotation speed of $300 \mathrm{rpm}$, the original signals are concluded in Fig.6. The rotation frequency $\mathrm{f}_{\mathrm{c}}=5 \mathrm{~Hz}$. Gear number is 34 . Thus the gear mesh frequency $\mathrm{f}_{\mathrm{n}}=5 \times 34=170 \mathrm{~Hz}$. Since the analysis frequency is $5000 \mathrm{~Hz}$, the wavelet decomposition level should set as $n=5$. Then the cD5 frequency band is $156 \mathrm{~Hz} 312 \mathrm{~Hz}$. This range includes gear mesh frequency which can be further analysised to diagnosis gear fault and monitoring gear health state.

As shown in Fig.7, after denoise and process the signal, cD5 fruquency band is extracted and reconstrutioned while eliminate other frequency bands.

Characteristic values of gear tooth working under different states are summarized in table.2. The tooth failure can be diagnosised by count factors combined with working condition informations. Firstly, I and L is smaller when gears working with loads. That is because load makes larger gear mesh force which will obviously increase the vibration. The force increase average amplitude and square root amplitude more than peak amplitude. Sencondly, I and L of gear tooth failure condition is bigger than health condition. That is because failure tooth makes transfer force uneven which will cause impact engergy. The result shows that wavelet analysis eliminated other frequency bands disturbing and makes characterize factors more effective.

$I_{\min }, I_{\max }, L_{\min }$ and $L_{\max }$ of multi work conditions are gained by experiment. Then the health index can be calculated based on I and L of current monitoring gear box. The on-line monitoring technology [9] has been developed fast in modern industry, thus it is convenient to adapt the method into practical condition. For example, after collecte the monitoring data and processed follow the procedure, current gear box $\mathrm{I}=5.5, \mathrm{~L}=6.5$, the work condition is $300 \mathrm{rpm}$ with load, then the health index can be calculated $\mathrm{H}=0.35$. The gear is in unhealthy state, it should be inspect more frequently. If the work condition is $300 \mathrm{rpm}$ without load, then $\mathrm{H}=0.48$. The gear is in middle level health state. It can be used normally. It can be concluded that the proposed procedure can quantitatively estimate the gear tooth health state which would effectively support gear box maintenance operation.
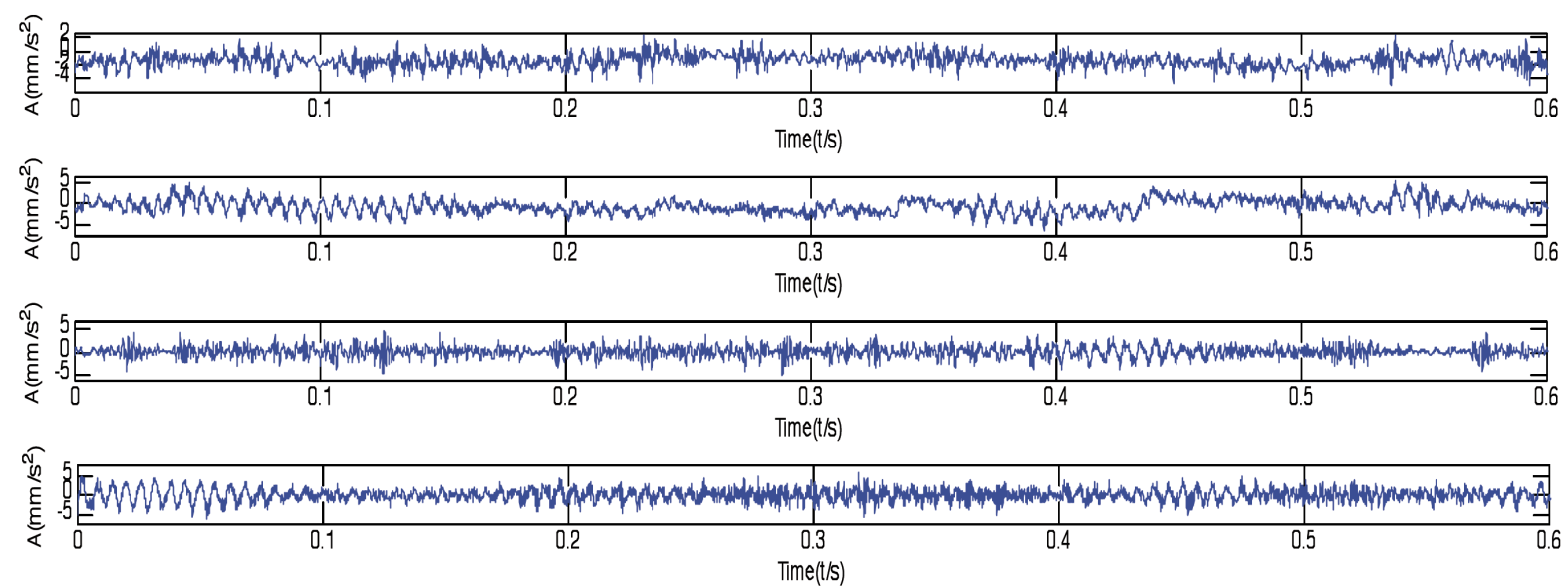

Figure 6. Original time-amplitude signal of $300 \mathrm{rpm}$ motor speed (A.Healthy state without load; B. Healthy state with load; C. Tooth failure state without load; D. Tooth failure state with load)
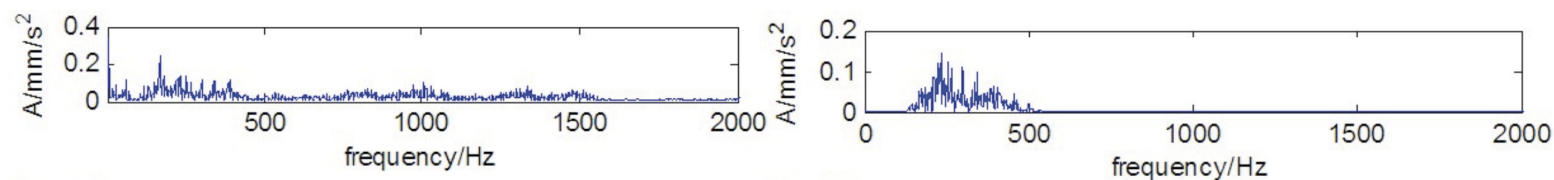

A
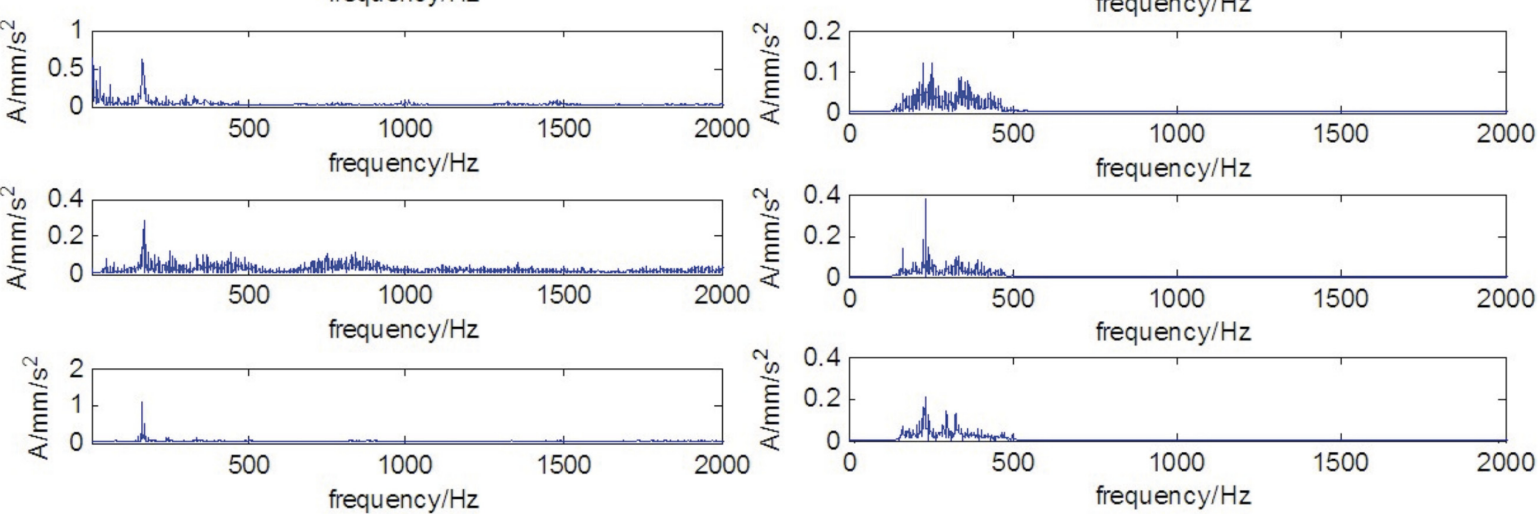

Figure 7. Frequency-amplitude figure of $300 \mathrm{rpm}$ motor speed (Figs on the left are orignal signals, figs on the right are signals after frequency extraction A. Normal state without load; B. Normal state with load; C. Tooth fail state without load; D. Tooth fail state with load) 
TABLE II.

FEATURE INDEXES OF SPECIAL FREQUENCY BAND UNDER VARYING WORK CONDITIONS

\begin{tabular}{|c|c|c|}
\hline Work conditions and states & Pulse index & Margin index \\
\hline $300 \mathrm{rpm} /$ Healthy/without load & 5.90 & 7.25 \\
\hline $300 \mathrm{rpm} /$ Tooth failure/without load & 6.90 & 8.27 \\
\hline $300 \mathrm{rpm} /$ Healthy/with load & 4.98 & 5.99 \\
\hline $300 \mathrm{rpm} /$ Tooth failure/with load & 6.15 & 7.57 \\
\hline $600 \mathrm{rpm} /$ Healthy/without load & 6.83 & 8.55 \\
\hline $600 \mathrm{rpm} /$ Tooth failure/without load & 8.49 & 10.74 \\
\hline $600 \mathrm{rpm} /$ Healthy/with load & 4.43 & 5.88 \\
\hline $600 \mathrm{rpm} /$ Tooth failure/with load & 6.49 & 7.85 \\
\hline
\end{tabular}

\section{ACKNOWLEDGMENT}

The authors would like to thank to the colleges of Research Center of Oil \& Gas Safety Engineering Technology for their incredible help and suggestions.

\section{REFERENCES}

[1] G. Li, X.W. Wang, L.H. Shi, "EMD Denoising Method and Its Application in Lamb Wave Detection,” Acta Metrologica Sinica, vol. 27, pp. 149-152, February 2006.

[2] T.H. Yi, H.N. Li, X.Y. Zhao, "Noise Smoothing for Structural Vibration Test Signals Using an Improved Wavelet Thresholding Technique," Sensors, vol.12, pp. 11205-11220, August 2012. http://dx.doi.org/10.3390/s120811205

[3] S. Li, X.D. Kang, J.W. Hu, B. Yang, "Image matting for fusion of multi-focus images in dynamic scenes," Inform. Fusion, vol. 14, pp. 147-162, April 2013. http://dx.doi.org/10.1016/j.inffus. 2011.07.001

[4] T. Radil, P.M. Ramos, F.M. Janeiro, A.C. Serra, "PQ monitoring system for real-time detection and classification of disturbances in a single-phase power system,” IEEE T. Instrum. Meas., vol. 57, pp. 1725-1733, August 2008. http://dx.doi.org/10.1109/TIM.2008 .925345

[5] L.Y. Zhao, H.S. Li, S.R. Wang, "The Silicon Micro-Gyroscope Signal Processing Method Based on Morphological Wavelet Filter," Information-TOKYO, vol. 15 issue 11A, pp. 4633-4640 November 2012.
[6] Y. Zhan, V. Makis, A.K.S. Jardine, “Adaptive state detection of gearboxes under varying load conditions based on parametric modelling,":Mech. Syst. Signal Pr., vol. 20, pp. 188-221, 2006. http://dx.doi.org/10.1016/j.ymssp.2004.08.004

[7] P. Maragos, R.W. Schafer, "Morphological fi1ters-Part II: Their relation to median, order-statistic, and stack filters," IEEE Trans. on ASSP, vol. 35, pp. 1170-1184, August1987. http://dx.doi.org/10.1109/TASSP.1987.1165254

[8] X.F. Fan, M.J. Zuo, "Gearbox fault detection using Hilbert and wavelet packet transform,” Mech. Syst. Signal Pr., vol.20, pp. 966-982, 2006. http://dx.doi.org/10.1016/j.ymssp.2005.08.032

[9] V. Gruber, R. Marcelino, J.B. Silva, "Technology PLC-power line communication, used in monitoring systems online," International Journal of Online Engineering, vol. 9, pp. 22-25, 2012

\section{AUTHORS}

H. Z. Feng is with China University of PetroleumBeijing, Beijing, China. (e-mail: fhz010@163.com).

W. Liang is the assistant dean of College of Mechanical and Transportation Engineering, China University of Petroleum-Beijing, Beijing, China (e-mail: lw@cup.edu.cn).

L. B. Zhang is the headmaster of China University of Petroleum-Beijing, Beijing, China. (e-mail: zhanglb@cup.edu.cn).

J. W. Shi is with China University of PetroleumBeijing, Beijing, China. (e-mail: 136645095@qq.com).

The research is supported by National Science and Technology Major Project of China (Grant No. 2011ZX05055), National Key Technology Research and Development Program of China (Grant No. 2011BAK06B01) and National Natural Science Foundation of China (Grant No. 51005247). This article is an extended and modified version of a paper presented at the International Conference on Mechanical Engineering, Automation and Material Science (MEAMS2012), held 2223 December 2012, Wuhan, China. Received 14 February 2013. Published as resubmitted by the authors 25 March 2013. 